\title{
EFICIÊNCIA DE METARHIZIUM ANISOPLIAE (METSCH.) SOROKIN NO CONTROLE DE DEOIS FLAVOPICTA (STAL., 1854), EM PASTAGEM DE CAPIM-BRAQUIÁRIA (BRACHIARIA DECUMBENS)
}

\section{M.F.A. Pereira1 ${ }^{1}$, R.A.L. Benedetti², J.E.M. Almeida ${ }^{3}$}

${ }^{1}$ APTA - Pólo Centro Norte, Unidade de Pesquisa e Desenvolvimento de Mirassol, Rod. Washington Luiz (SP 310), km 445, CEP 15025-990, São José do Rio Preto, SP, Brasil. E-mail: mfapereira@apta.sp.gov.br

\section{RESUMO}

\begin{abstract}
Com o objetivo de avaliar a eficiência da aplicação de doses do fungo Metarhizium anisopliae (isolado IBCB 425) no controle da cigarrinha-das-pastagens Deois flavopicta, foi conduzido um ensaio de campo em pastagem de capim-braquiária (Brachiaria decumbens), no Município de Itatinga, SP, no período de fevereiro a maio de 2006. Arroz contendo M. anisopliae esporulado foi lavado em água, coado e aplicado a partir das $17 \mathrm{~h}$, sob temperatura média de $18^{\circ} \mathrm{C}$ e umidade relativa de $69 \%$. O volume de calda utilizado foi de $300 \mathrm{~L} \mathrm{ha}^{-1}$. As avaliações procederam-se aos 14,29 e 44 dias após a aplicação do entomopatógeno, contando-se as cigarrinhas (ninfas) por ponto de $0,0625 \mathrm{~m}^{2}$ (quadrado de $0,25 \mathrm{~m} \times 0,25 \mathrm{~m}$ ). Pelos resultados obtidos, conclui-se que $M$. anisopliae

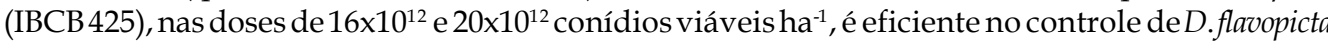
em pastagem de capim-braquiária (B. decumbens).
\end{abstract}

PALAVRAS-CHAVE: Cigarrinha-das-pastagens, fungo entomopatogênico, controle biológico, controle microbiano, manejo integrado de pragas.

\section{ABSTRACT}

EFFICIENCY OF METARHIZIUM ANISOPLIAE(METSCH.)SOROKINONTHECONTROLOF DEOIS FLAVOPICTA (STAL., 1854), IN BRACHIARIA DECUMBENS PASTURE. This study was carried out to evalute the efficiency of the entomopathogenic fungiMetarhizium anisopliae (isolate IBCB 425) for control of spittlebug Deois flavopicta. The test was carried out under field conditions, in Brachiaria decumbens pasture, in Itatinga, São Paulo State, Brazil, from February to May 2006. Grain rice containing sporulated $M$. anisopliae was washed in water, strained and applied in 5 doses, after $17 \mathrm{~h}$, under average temperature and relative air humidity of $18^{\circ} \mathrm{C}$ and $69 \%$, respectively, at the volume of $300 \mathrm{~L} \mathrm{ha}^{-1}$. Evaluations were performed 14, 29 and 44 days after applications, counting the spittlebugs (nymphs) per $0.0625 \mathrm{~m}^{2}(0.25 \mathrm{~m} \times 0.25 \mathrm{~m}$ square). The results showed that M. anisopliae (IBCB 425), at doses of $16 \times 10^{12}$ and $20 \times 10^{12}$ viable conidias ha- ${ }^{-1}$, is effective for the control of $D$. flavopicta, in B. decumbens pasture.

KEY WORDS: Spittlebug, entomopathogenic fungi, biological control, microbial control, integrated pest management.

\section{INTRODUÇÃO}

A adaptação de gramíneas do gênero Brachiaria (Poaceae) às condições de baixa fertilidade e alta acidez de solos do cerrado brasileiro resultou no cultivo extensivo de capins-braquiária. Com o passar do tempo, verificou-se a suscetibilidade de Brachiaria decumbens, B. ruziziensis, B. dyctioneura e B. humidicola às cigarrinhas-das-pastagens, consideradas princi- pais pragas de gramíneas forrageiras na América Tropical (COSENZA, 1981; VALÉRIO; NAKANO, 1988; FONTES et al., 1995, DuARTE et al., 2007) e, a partir da década de60, estes insetos-praga passaram a ser relatados em todo o Brasil (EMBRAPA, 1977; SANTOs et al., 1982).

Das espécies de cigarrinhas que atacam pastagens, Deois flavopicta (Hemiptera: Cercopidae) ocorre com maior freqüência nas regiões Sudeste e CentroOeste do Brasil (Fontes etal., 1995; VALÉRIO et al.,2000).

${ }^{2}$ Cutrale - Fazenda Rosana, Avaré, SP, Brasil.

${ }^{3}$ Instituto Biológico, Centro Experimental Central, Campinas, SP, Brasil. 
O adulto deste cercopídeo possui asas pretas com duas faixas transversais amarelas e uma faixa longitudinal também amarelada em cada asa anterior, além de abdome e pernas avermelhados. As fêmeas ovipositam no solo ou em restos de vegetação e, após a eclosão, as ninfas se fixam na base do capim e ficam protegidas por espuma característica (PEREIRA; PereIRA, 1985; ZuCCHI et al., 1993). A cigarrinha requer calor e umidade para se desenvolver e proliferar. Portanto, sua ocorrência se dá durante o período chuvoso, podendo ocorrer de três a cinco gerações anuais, dependendo das condições climáticas (COSENZA, 1989; FonTEs et al., 1995).

A ação das cigarrinhas nas pastagens tem início na fase de ninfa, quando sugam a seiva de raízes e caules próximos à superfície do solo. Os adultos, ao sugarem as folhas, injetam secreções salivares que causam fitotoxemia, provocando amarelecimento das folhas com posterior secamento e morte. Reduzem o crescimento da planta, diminuindo a produção de forragem e, conseqüentemente, a capacidade de suporte. Além dos prejuízos quantitativos, a cigarrinha reduz os teores de proteína bruta, gordura e minerais essenciais e aumenta matéria seca, tornando a gramínea menos palatável. Com isso, o animal come menos, deixando de produzir leite e carne (PEREIRA et al., 1982; HEWITT, 1988; VALÉRIO; NAKANO, 1988; TÔNUS, 1999). No Brasil, Silveira Netoet al. (1992) citaram a ocorrência de cigarrinhas em cerca de 10 milhões de hectares de pastagens, provocando prejuízos variáveis entre 10 e $100 \%$, dependendo da espécie, tipo de gramínea, condições climáticas e manejo.

O uso de táticas de manejo visando a diminuição e/ ou equilíbrio populacional da cigarrinha-das-pastagens torna-se indispensável, principalmente em variedades de capins suscetíveis. Assim, o controle biológico se destaca entre os métodos disponíveis para o manejo de pastagens atacadas pelo insetopraga (Pereira; Pereira, 1985; Melo; Azevedo, 1998). Dentre os agentes de controle biológico, o fungo entomopatogênico Metarhizium anisopliae, de ocorrência natural no Brasil, vem sendo cada vez mais utilizado no controle de pragas (AlvEs, 1998). A ação do patógeno sobre cigarrinha-das-pastagens foi constatada naturalmente e comprovada em laboratório (Ventura; Matioli, 1980; Villacorta, 1980) e sua recomendação para o manejo da praga em pastagens é comum entre autores. Todavia, vale ressaltar que a inconsistência de resultados em relação à eficácia do fungo também tem sido reportada e, segundoSILVEIRA Neto et al. (1992) e FRANCO (2002), isto pode estar relacionado à qualidade e tipo de isolado utilizado, quantidade do fungo aplicada por unidade de área, problemas de formulação e armazenamento, método de aplicação, descumprimento das recomendações de uso e variações ambientais inesperadas.
Entretanto, apesar do potencial de M. anisopliae para o manejo de D. flavopicta em pastagens, a principal limitação ao uso mais generalizado dessa tecnologia diz respeitoà inconsistência de resultados a campo. Assim, o objetivo deste trabalho foi avaliar a eficiência da aplicação de doses do bioinseticida $M$. anisopliae (isolado IBCB 425) no controle de $D$. flavopicta, em pastagem de capim-brachiária ( $B$. decumbens).

\section{MATERIAL E MÉTODOS}

Para avaliar o controle da cigarrinhaD.flavopicta, mediante aplicação de doses do fungo $M$. anisopliae (isolado IBCB 425), foi conduzido um ensaio de campo em pastagem de capim-braquiária (B.decumbens), no Município de Itatinga, SP, no período de fevereiro a maio de 2006.

O modelo experimental utilizado foi em faixas (8 $\mathrm{m} \times 50 \mathrm{~m}$ ), com sete tratamentos e 16 repetições constituídas por pontos de amostragem de 0,0625 $\mathrm{m}^{2}$ (quadrado de 0,25 $\mathrm{m} \times 0,25 \mathrm{~m}$ ), distribuídos ao acaso em cada tratamento. O número de pontos de amostragem foi adotado de acordo com Menezes et al. (1983) e, a área do ponto amostral conforme NiLAKHE (1982). Os tratamentos consistiram de doses do fungo M. anisopliae em calda $\left(4 \times 10^{12}, 8 \times 10^{12}, 12 \times 10^{12}, 16\right.$ x $10^{12}$ e $20 \times 10^{12}$ conídios viáveis por hectare), do inseticida clorpirifós a $0,480 \mathrm{~kg} \mathrm{ha}^{-1}$ e testemunha (sem aplicação de defensivo).

O isolado IBCB 425 de M. anisopliae foi obtido de solo de Mata Atlântica, de Iporanga, SP, e analisado quanto à virulência sobre a cigarrinha da cana-de-açúcar e pastagensMahanarvafimbriolata, junto ao Laboratório de Controle Biológico, do Centro Experimental Central do Instituto Biológico, Campinas, SP. Posteriormente, foi produzido em arroz pré-cozido e autoclavado, na concentração de 4,0 x $10^{9}$ conídios g $^{-1}$ e viabilidade de 96,7\%, por empresa que comercializa o produto. No dia da aplicação, o bioinseticida foi transportado em caixa de isopor.

Para aplicação, o fungo esporulado em arroz foi lavado em água, coado em peneiras de arroz e, em seguida, verteu-se a calda no tanque de pulverizador costal, equipado com pontas de pulverização do tipo LPBD 8002, aplicando-se 300 L de calda por hectare. A técnica de aplicação se fez em função do hábito das ninfas da cigarrinha e, conforme Alves (1998), da ação de contato do inseticida microbiano. Ainda, considerando a ação prejudicial dos raios solares ao fungo entomopatogênico, o bioinseticida foi aplicado a partir das $17 \mathrm{~h}$, sob temperatura média de $18^{\circ} \mathrm{C}$ e umidade relativa de $69 \%$. O inseticida clorpirifós foi aplicado na manhã do dia seguinte. 
Na instalação do experimento, a pastagem encontrava-se com infestação média de 65,86 insetos por $\mathrm{m}^{2}$, acima do nível de 20 a 25 insetos por $\mathrm{m}^{2}$ recomendado para o controle de cigarrinhas em pastagens de capim-brachiária (Menezes et al., 1983; CAMPanhola; Bettiol, 2003).

As avaliações procederam-se previamente (3/3/ 2006), aos 14 (18/3/2006), 29 (2/4/2006) e 44 (17/4/ 2006) dias após a aplicação de $M$. anisopliae, contando-se as ninfas de cigarrinhas por ponto de $0,0625 \mathrm{~m}^{2}$. Para facilitar a contagem, os insetos foram retirados da região radicular com auxílio de palito de madeira.

Os dados foram extrapolados para número de cigarrinhas por $\mathrm{m}^{2} \mathrm{e}$, após serem transformados em $\log$ de $(x+10,00)$, efetuou-se a análise de variância pelo teste $\mathrm{F}$ e comparação de médias pelo teste de Tukey a $5 \%$ de probabilidade. A eficiência dos defensivos foi calculada por meio da fórmula proposta por Аввотт (1925).

\section{RESULTADOS E DISCUSSÃO}

Previamente à aplicação dos defensivos, em 3/3/ 2006, não foi constatada diferença significativa quanto ao número médio de cigarrinhas na área experimental (Tabela 1), observando-se uma uniformidade na distribuição do inseto-praga.

M. anisopliae em calda, na dose de $20 \times 10^{12}$ conídios viáveis por hectare, reduziu a população de $D$. flavopicta em relação à pastagem sem aplicação de defensivo (testemunha), logo aos 14 dias após a aplicação (DAA) (Tabela 1), com 62,03\% de mortalidade
(Fig. 1), igualando, significativamente, ao inseticida clorpirifós, que se destacou no controle do insetopraga, com eficácia de 70,89\%.

Aos 29 DAA, foi constatada menor infestação de cigarrinhas em pastagens pulverizadas $\operatorname{com} 8,16$ e 20 x $10^{12}$ conídios viáveis de $M$. anisopliae por hectare, assim como na área submetida à aplicação de clorpirifós, em relação à área sem aplicação de defensivo. O bioinseticida, nas doses de 16 e $20 \times 10^{12}$ conídios viáveis ha-1, apresentou eficácia de 83,33 e $77,08 \%$ de controle do inseto-praga, respectivamente, assemelhando-se ao inseticida químico.

Apesar de o inseticida microbiano, nas doses de 8, 16 e $20 \times 10^{12}$ conídios viáveis ha $^{-1}$, ter apresentado porcentagem de mortalidade superior a $85 \%$, aos $17 /$ 4/2006 (44 DAA), não foi constatada diminuição significativa quanto ao número médio de ninfas de $D$. flavopicta em relação à população verificada na pastagem sem aplicação de defensivo. Isto ocorreu, provavelmente, devido à pequena população do inseto no capim-braquiária no início da época "seca", considerada, conforme SiLveira Neto et al. (1992); FONTES et al. (1995) e PirEs et al. (2000), desfavorável à reprodução e desenvolvimento de cercopídeos.

Considerando o total de cigarrinhas após aplicação dos defensivos, evidencia-se a ação do fungo $M$. anisopliae, nas doses de 16 e $20 \times 10^{12}$ conídios viáveis $\mathrm{ha}^{-1}$ sobre o inseto-praga, semelhantemente ao inseticida químico. Em geral, o entomopatógeno foi eficiente no controle de D. flavopicta, nas respectivas doses, com média superior a $71 \%$ de mortalidade, corroborando com a eficácia de controle de 60 a 80\% do agente microbiano, citada em FRANCO (2002).

Tabela 1 - Número médio de ninfas deDeois flavopicta por metro quadrado de pastagem deBrachiaria decumbenssubmetida à aplicação de Metarhizium anisopliae. Itatinga, SP, 2006.

\begin{tabular}{lllllcc}
\hline Tratamento & Dose ha $^{-1}$ & \multicolumn{4}{c}{ Avaliação (dias após a aplicação) } \\
\cline { 3 - 7 } & & 0 & 14 & 29 & 44 & Total \\
\hline M. anisopliae & $4 \times 10^{12,1}$ & $69^{2,3}$ & $74 \mathrm{a}$ & $29 \mathrm{ab}$ & $8 \mathrm{a}$ & $111 \mathrm{ab}$ \\
M. anisopliae & $8 \times 10^{12}$ & 60 & $69 \mathrm{ab}$ & $18 \mathrm{~b}$ & $0 \mathrm{~b}$ & $87 \mathrm{abc}$ \\
M. anisopliae & $12 \times 10^{12}$ & 92 & $88 \mathrm{a}$ & $24 \mathrm{ab}$ & $6 \mathrm{ab}$ & $118 \mathrm{a}$ \\
M. anisopliae & $16 \times 10^{12}$ & 61 & $42 \mathrm{abc}$ & $8 \mathrm{~b}$ & $1 \mathrm{ab}$ & $51 \mathrm{bcd}$ \\
M. anisopliae & $20 \times 10^{12}$ & 53 & $30 \mathrm{bc}$ & $11 \mathrm{~b}$ & $1 \mathrm{ab}$ & $42 \mathrm{~cd}$ \\
clorpirifós & 0,480 & 53 & $23 \mathrm{c}$ & $7 \mathrm{~b}$ & $0 \mathrm{~b}$ & $30 \mathrm{~d}$ \\
testemunha & --- & 73 & $79 \mathrm{a}$ & $48 \mathrm{a}$ & $7 \mathrm{ab}$ & $134 \mathrm{a}$ \\
\hline F (tratamentos) & & $1,00 \mathrm{~ns}$ & $6,96^{* *}$ & $5,23^{* *}$ & $3,45^{* *}$ & $12,41^{* *}$ \\
C.V. (\%) & & 20,27 & 20,65 & 23,01 & 15,60 & 16,88 \\
\hline
\end{tabular}

${ }^{1}$ Dose de M. anisopliae em conídios viáveis e de clorpirifós em $\mathrm{kg}$.

${ }^{2}$ Valores originais. Para análise, os dados foram transformados em log de $(x+10,00)$.

${ }^{3}$ Médias seguidas de mesma letra, na coluna, não diferem entre si pelo teste de Tukey $(\mathrm{P} \leq 0,05)$.

ns - não significativo.

** - significativo a $1 \%$ de probabilidade. 


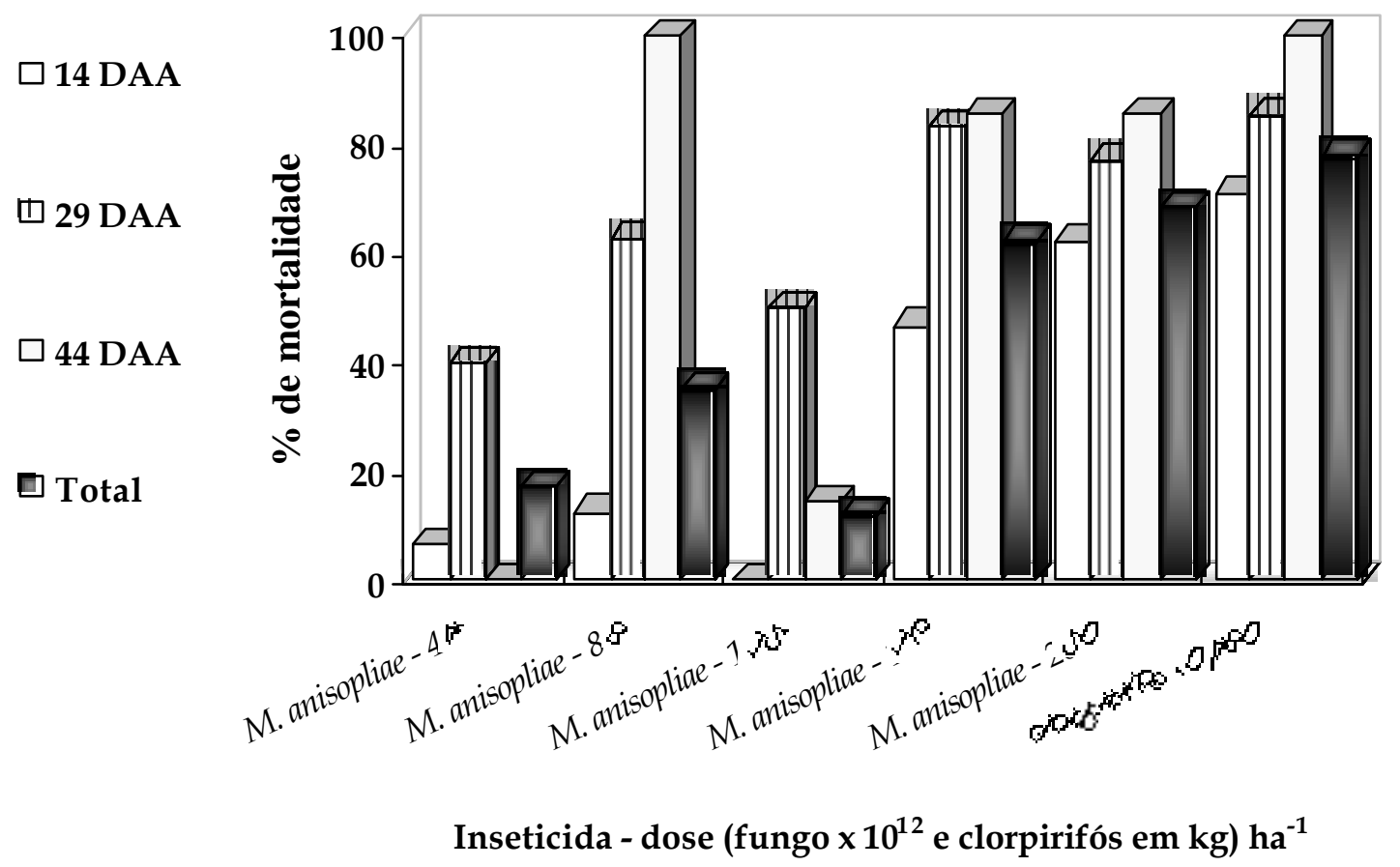

Fig. 1 - Mortalidade de ninfas deDeoisflavopicta em pastagem deBrachiariadecumbens submetida à aplicação deMetarhizium anisopliae, em dias após aplicação (DAA). Itatinga, SP, 2006.

Assim, M. anisopliae (isolado IBCB 425) apresenta-se como alternativa para o manejo de $D$. flavopicta em pastagens. Ainda, de acordo com СRосомо(1990), por se tratar de um método biológico, vale ressaltar a importância da supressão populacional do insetopraga de forma econômica e harmoniosa com o meio ambiente. Para tanto, embora neste estudo a aplicação do bioinseticida tenha sido efetuada no último pico populacional da praga, cumpre mencionar a importância da utilização do agente microbiano nos primeiros picos populacionais da cigarrinha-daspastagens, considerando o nível de controle recomendado.

\section{CONCLUSÃO}

Nas condições climáticas e de infestação em que o ensaio de campo foi conduzido, pode-se concluir que: M. anisopliae (isolado IBCB 425), nas doses $16 x$ $10^{12} \mathrm{e} 20 \times 10^{12}$ conídios viáveis por hectare, é eficiente no controle de D. flavopicta, em pastagem de capimbraquiária (B. decumbens).

\section{AGRADECIMENTO}

À Empresa Toyobo do Brasil, pelo fornecimento do fungo M. anisopliae para o estudo.

\section{REFERÊNCIAS}

ABBOTT, W.S. A method of computing the effectiveness of an insecticide. Journal of Economic Entomology, v.18, n.1, p.265-267, 1925.

ALVES, S.B. Patologia e controle microbiano: vantagens e desvantagens. In: ALVES, S.B. (Ed.). Controle microbiano de insetos. 2.ed. Piracicaba: FEALQ, 1998. p.21-37.

CAMPANHOLA, C.; BETTIOL, W. Controle biológico de pragas e técnicas alternativas. In: CAMPANHOLA, C.; BETTIOL, W. (Ed.). Métodos alternativos de controle fitossanitário. Jaguariúna: EMBRAPA-CNPMA, 2003. p.97-163.

COSENZA, G.W. Resistência de gramíneas forrageiras à cigarrinha-das-pastagens Deois flavopicta (Stal., 1854). Planaltina: EMBRAPA-CPAC, 1981. 16p. (Boletim de Pesquisa, 7).

COSENZA, G.W. Biologia e ecologia de pragas das pastagens. In: SIMPÓSIO SOBRE ECOSSISTEMA DE PASTAGENS, 1989, Jaboticabal, SP. Anais. Jaboticabal: FUNEP, 1989. p.87-96.

CROCOMO, W.B. Manejo integrado de pragas. São Paulo: Unesp, 1990. 358p.

DUARTE, M. de L.R.; ALBUQUERQUE, F.C.; SANHUEZA, R.M.V.; VERZIGNASSI, J.R.; KONDO, N. Etiologia da podridão do coleto de Brachiaria brizantha 
em pastagens da amazônia. Fitopatologia Brasileira, v.32, n.3, p.261-265, 2007.

EMBRAPA. Programa nacional de controle às cigarrinhasdas-pastagens. Brasília: EMBRAPA, 1977. 17p.

FONTES, E.G.; PIRES, C.S.S.; SUJII, E.R. Mixed riskspreading strategies and the population dynamics of a Brazilian pasture pest, Deois flavopicta (Homoptera: Cercopidae). Journal of Economic Entomology, v.88, n.5, p.1256-1262, 1995.

FRANCO, M. Cigarrinha: a praga que volta com as chuvas. DBO rURAL, n.264, p.86-90, 2002.

HEWITT, G.B. Grazing management as a means of regulating spittlebug (Homoptera: Cercopidae) numbers in Central Brazil. Pesquisa Agropecuária Brasileira, v.23, n.7, p.697-707, 1988.

MELO, I.S.; AZEVEDO, J.L. Controle biológico. Jaguariúna: EMBRAPA-CNPMA, 1998. 264p.

MENEZES, M. de; EL-KADI, M.K.; PEREIRA, J.M.; RUIZ, M.A.M. Bases para o controle integrado das cigarrinhas-das-pastagens na região Sudeste da Bahia. Ilhéus: CEPLAC-CEPEC, 1983. p.1-36. (Boletim Avulso da Ceplac).

NILAKHE, S.S. Amostragem de ninfas de cigarrinhas em pastagens de Brachiaria decumbens Stapf. Campo Grande: EMBRAPA-CNPGC, 1982. 67p. (Boletim de Pesquisa, 2).

PEREIRA, J.C.R.; NAZAR, R.A.; ARMOUND, W.B. Interrelacionamento de macro e micronutrientes com diferentes densidades de cigarrinhas-das-pastagens. Belo Horizonte: Divisão de Defesa Sanitária Vegetal, 1982. 15p.

PEREIRA, J.R.; PEREIRA, J.C.R. Cigarrinha das pastagens: importância e métodos de controle para a Zona da Mata de Minas Gerais. Coronel Pacheco: EMBRAPACNPGL, 1985. 23p. (Circular Técnica, 25).

PIRES, C.S.S.; SUJII, E.R.; FONTES, E.M.G.; TAUBER, C.A.; TAUBER, M.J. Dry-season embryonic dormancy in Deois flavopicta (Homoptera: Cercopidae): Roles of temperature and moisture in nature. Enviromental Entomology, v.29, n.4, p.714-720, 2000.

SANTOS, P.J.; BOTELHO, W.; CRUZ, I. Avaliação de dano e controle da cigarrinha-das-psatagens em plantas de milho com diferentes idades. Sete Lagoas: EMBRAPA - CNPMS, 1982. $8 \mathrm{p}$.

SILVEIRA NETO, S.; MARCHINI, L.C.; ALVES, S.B. Pragas das pastagens. In: CURSO DE ENTOMOLOGIA APLICADA À AGRICULTURA, 1992, Piracicaba, SP. Anais. Piracicaba: Fealq, 1992. p.335-353.

TÔNUS, M. Manejo integrado controla cigarrinhas em pastagens. Balde Branco, n.421, p.38-45, 1999.

VALÉRIO, J.R.; NAKANO, O. Danos causados pelo adulto da cigarrinha Zulia entreriana na produção e qualidade de Brachiaria decumbens. Pesquisa Agropecuária Brasileira, v.23, n.5, p.447-453, 1988.

VALÉRIO, J.R.; SOUZA, O.C. de; VIEIRA, J.M.; CORRÊA, E.S. Diagnóstico de morte de pastagens nas regiões central e norte do Estado de Mato Grosso. Campo Grande: EMBRAPA - CNPGC, 2000. 10p. (Documentos, 98).

VENTURA, J.A.; MATIOLI, J.C. Ocorrência de epizootias naturais causadas por Metarhizium anisopliae (Metsch) Sorok. em populações de Zulia entreriana (Berg., 1879) e Deois sp. no Estado do Espírito Santo. Ecossistema, v.5, n.1, p.92-95. 1980.

VILLACORTA, A. Susceptibilidade de ninfas de Deois flavopicta (Stal, 1854) (Homoptera: Cercopidae) a diferentes isolamentos de Metarhizium anisopliae (Metsh.) Sorokin. Anais da Sociedade Entomológica do Brasil, v.9, n.1, p.33-38, 1980.

ZUCCHI, R.A.; SILVEIRA NETO, S.; NAK ANO, O. Guia de identificação de pragas agrícolas . Piracicaba: Fealq, 1993. 193p.

Recebido em 14/3/07

Aceito em 7/11/08 